\title{
Investigating the Use of Learning Management System (LMS) for Distance Education in Malaysia: A Mixed-Method Approach
}

\author{
Nagaletchimee Annamalai \\ School of Distance Education, Universiti Sains Malaysia, Pulau Pinang, Malaysia \\ ORCID: 0000-0002-8600-5624 \\ T. Ramayah \\ School of Management, Universiti Sains Malaysia, Pulau Pinang, Malaysia \\ ORCID: 0000-0002-7580-7058 \\ Jeya Amantha Kumar \\ Centre for Instruction Technology and Multimedia, Universiti Sains Malaysia, Pulau Pinang, Malaysia \\ ORCID: 0000-0002-6920-0348 \\ Sharifah Osman \\ Faculty of Social Sciences and Humanities, School of Education, Universiti Teknologi Malaysia, Skudai, Johor, \\ Malaysia \\ ORCID: 0000-0003-2896-9377
}

Received: 16 Feb 2021

Accepted: 25 Apr 2021

\begin{abstract}
Technology acceptance research explains the adaptation of learning technology by accounting for the use of technologies. This mixed-method study investigated the use of Learning Management Systems (LMS) for distance education in Malaysia using the extended Technology Acceptance Model (TAM). Limited studies on LMS for Malaysia higher education studies focusing on distance learning are warranted due to the diversity of resources, maturity, and education as working adults contrasting from traditional undergraduates. The survey on 205 respondents revealed that the extended TAM, which includes perceived resources, explained variance in attitudes $\left(R^{2}=56.2 \%\right)$ and actual use $\left(R^{2}=34.5 \%\right)$ adequately. Concurrently, indicating perceived ease of use and perceived resources as a determiner for the attitude which predicts actual use. Subsequently, a semi-structured interview on 15 respondents supported this as it was inferred that respondents' attitude was mainly determined by their perception of the role of LMS to facilitate learning activities. Furthermore, inconveniences in accessing learning contents and lack of interactive learning activities are the respondents' primary concern, reflecting on the predictive role of perceived ease of use. The findings also provide appropriate guidance for the pedagogical design and LMS implementation for distance education based on affordance and inclusivity.
\end{abstract}

Keywords: extended TAM, perceive resources, distance learning, Moodle, higher education

\section{INTRODUCTION}

Learning Management System (LMS) such as BlackBoard, Moodle, and WebCT are popular virtual learning environments in higher education and have been adopted globally to integrate teaching and learning technology. The benefits include flexibility, ubiquity, time, and cost-efficiency (Fernando et al., 2008; Park \& Choi, 2009). It was initially focused on distance learning (Cigdem \& Ozturk, 2016), as it provided a means to 
diversify the learning population based on $21^{\text {st }}$-century learning needs (Bervell \& Arkorful, 2020; Saidi et al., 2021). Nevertheless, LMS has come a long way. Its functionality has expanded to facilitate the integration of online tools for hybrid learning, such as flipped and blended learning (Washington, 2019). Despite these strengths, LMS is not free from pessimism. While beneficial, the online delivery using LMS requires strategies that could facilitate different learning requirements and styles (Thah \& Latif, 2020) which falls upon the instructors' hands to create a meaningful learning experience (Cigdem \& Ozturk, 2016; Kim \& Thayne, 2015). As LMS is also designed to be instructor-oriented, empirical findings have indicated that it restricts learners from exploring the learning facilities independently (Viberg \& Grönlund, 2017). Furthermore, its inadequacy as an effective communication and interaction platform (Gros \& García-Peñalvo, 2016) reflects substandard opportunities as a collaborative tool (Fleischmann, 2018).

Likewise, issues were also apparent in terms of usability as older LMS versions were mainly designed for desktop-based interaction while not supporting mobile accessibility (Viberg \& Grönlund, 2017). When a majority of undergraduates today are avid users of smartphones (Annamalai \& Kumar, 2020), the unavailability of quick mobile access and unresponsive design tends to negatively affect the success of the platform (Abdul Lasi, 2021; Kumar et al., 2020; Kumar \& Al-Samarraie, 2018). Moreover, due to this need, factors relating to resources such as the internet, devices, and access have played a crucial role in the intention to use an information system (Zwain, 2019). According to Yacob et al. (2020), in Malaysia, these technology barriers have been critical in influencing LMS use for distance education. Henceforth, indicating ICT infrastructures as one of the main factors for successful implementation of LMS, especially in higher learning institutions (Sobaih et al., 2016). Furthermore, Chung et al. (2020) and Thah and Latif (2020) also found that other perceived resources in learning such as online communication strategies, content, interaction, and accessibility to video streaming platforms are some of the factors that influence the use of LMS for distance education in Malaysia.

\section{PROBLEM STATEMENT}

Understanding factors that influence students' actual use of LMS becomes critical as such insights into their behavior could be used to improve students' online learning experience and future LMS expansion (Thah \& Latif, 2020). Similar studies in Malaysia have warranted investigating acceptance and readiness as there is a lack of learner control and communication in using LMS for distance education (Chung et al., 2020). According to Yacob et al. (2020), barriers relating to technology, internet, device, and skills have been instrumental in influencing LMS use for distance-learning where students have opted for mobile learning strategies such as WhatsApp and Google Classroom than using traditional LMS. Henceforth, understanding these factors is vital for distance learning, as LMS is the primary platform used to facilitate teaching and learning. A more complex argument is that distance education students' diversity due to resources, location (Almarashdeh \& Alsmadi, 2016), maturity, education background, and technology application may differ from how traditional students perceive online teaching and learning. Henceforth, highlighting the need to explore factors determining utilization and behaviors that would determine their acceptance and future use of LMS as an online learning platform.

\section{RESEARCH OBJECTIVES}

Therefore, the present study aims to examine attitude and the actual use of LMS among Malaysian distance learning students. For this reason, the Technology Acceptance Model (TAM) was used as a baseline model as empirical findings have indicated ease of access, quality of learning experience, and resources as primary factors influencing the use of LMS. Additionally, as studies related to LMS and distance education in Malaysian (Abdul Lasi, 2021; Chung et al., 2020; Yacob et al., 2020) mainly focused on quantitative research, we focused on a mixed-method strategy. We stipulate that a qualitative approach by understanding perceived benefits, challenges, and recommendations will further determine their use behavior. Therefore, while the general objective of this study is to investigate factors affecting intentions and behavior of distance education students use of LMS, the specific objectives are: 
i. To examine the relationship between perceived usefulness, perceived ease of use, and perceived resources on LMS use behavior and behavioral intention for distance education.

ii. To investigate perceived benefits and challenges of using LMS for distance education and their recommendation to improve their interaction.

\section{LITERATURE REVIEW}

\section{Learning Management System (LMS)}

In this study, the institution's central LMS platform is a Moodle-based platform. The Moodle environment involves asynchronous discussion that allows students to use their time for thinking, planning, interacting, formulating ideas, and participating in forums and quizzes. According to Waheed et al. (2016), the most frequently utilized features of Moodle are Communication Module, Assignment Module, Course Content Module, and Couse Delivery Module. The Course Content Module refers to course compilation, which demands students to be involved in the regular learning process (Brophy, 1999), and Assignment Module allows for assignment submission and grading facility (Aybay \& Dağ, 2003). Moodle as a tool for distance learning has been fundamental as these modules have been instrumental in innovating learning by providing a platform to manage the learning process through compelling interactivity (Mukoviz et al., 2019). Empirical studies have documented positive learning outcomes (Novo-Corti et al., 2013) and positive perception on usefulness and ease of use (Escobar-Rodriguez \& Monge-Lozano, 2012) by using Moodle in higher institutions. We agree that while the research foundation on LMS and the online learning environment is rich, not all issues and barriers have been amply identified and addressed, which leaves room for further investigation.

\section{Technology Acceptance Model (TAM)}

Technology Acceptance Model (TAM) was first introduced by Davis (1985) based on the theory of reasoned action and theory of planned behaviour, and it has supported a multitude of studies related to acceptance of technology (Weng et al., 2018). TAM is widely used to investigate the acceptance of end-user in computing technologies (Sivo et al., 2018) in education (Weng et al., 2018). The model associates with perceived usefulness (PU), perceived ease of use (PEOU), and Attitude (AT) towards using the technology. Davis et al. (1989) defined PEOU as the degrees to which an individual believes that using specific technology would be free from effort, whereas PU relates to perceived usefulness to improve performance. Lastly, AT is defined as the degree to which users are interested in a specific system (Davis, 1985).

In regard to TAM application in online learning, Ifinedo et al. (2018) reported that the usability factors have a positive effect on learners' actual use compared to PEOU and PU. Empirical findings have also indicated that PEOU, not PU as the main factor influencing the use of technology (Al-Busaidi, 2013). At the same time, Tarhini et al. (2015) indicated that PU is the strongest determinant for acceptance in this context. Concurrently, Bervell and Umar (2018) highlighted the need to explore distance education students' attitudes regarding LMS use behavior. While PEOU and PU positively affect the use and Attitude of LMS for distance education students, further investigation on other possible external factors that influence actual use is still warranted (Almarashdeh \& Alsmadi, 2016). However, Sivo et al. (2018), referring to the Extended TAM model, described how external variables might contribute to PEOU and PU. One such external variable, referred to as perceived resources (PR), was fundamental towards learning and system acceptance (Morris \& Venkatesh, 2010). It was also reported that perceived resources are critical determinants toward adopting technology (Smith \& Sivo, 2012). Mathieson et al. (2001), through their Extended TAM model (Figure 1), showed that resources such as skills, time, money, hardware, software, human assistance, and data are critical in influencing the use of a system. Therefore, PR is defined as the perceived belief that resources available individually and/or through an organization are crucial to using a system (Sivo et al., 2018). Mathieson et al. (2001) found that resources affect individuals' ease of use, behavioral intention and portray a small effect on usefulness, whereas Lee (2008) confirmed that perceived resources could lead to better online adoption. 


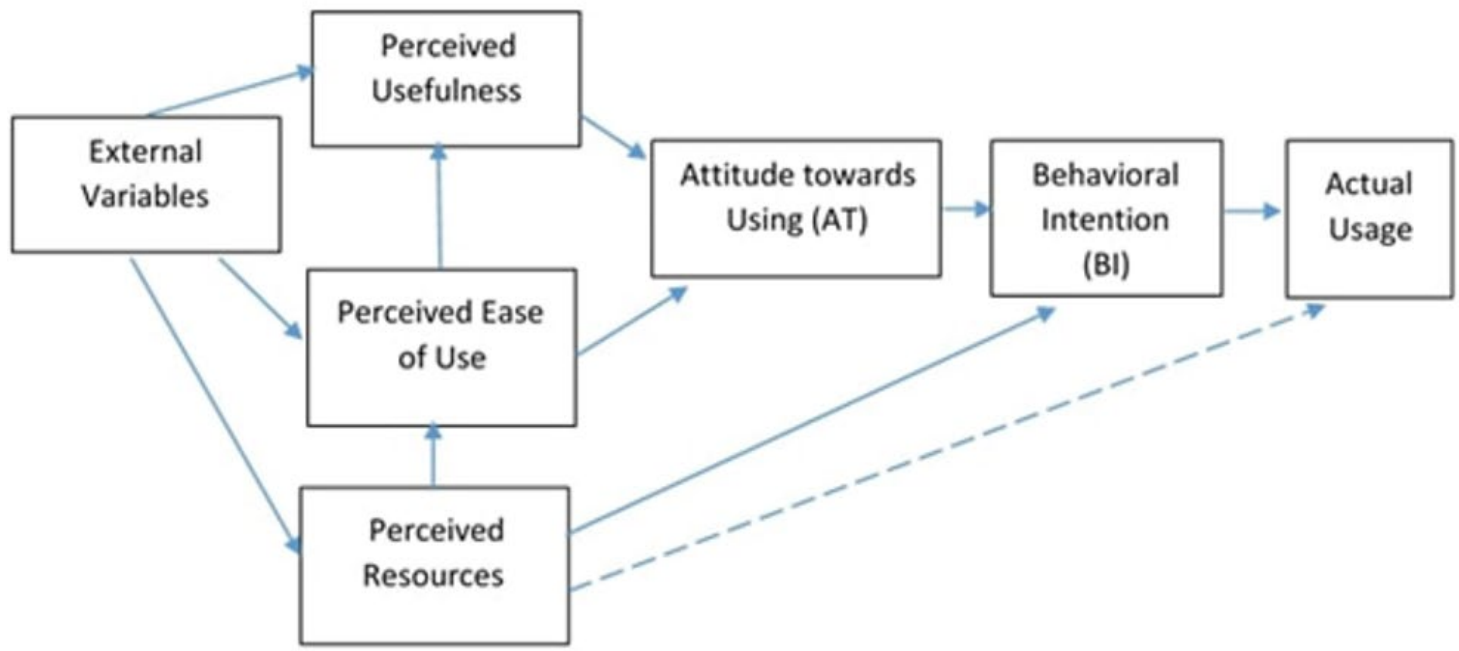

Figure 1. Extended TAM (Mathieson et al., 2001, p. 92)

Referring to the extended TAM, two constructs were removed from our study: (i) external variables and (ii) behavioral intention. Firstly, for external variables, Ku (2009) claims that there are reduced effects of external variables with time when using LMS. This was initially proposed by Hubona et al. (1996), claiming that external variables based on individuals and organizations are crucial only when a new technology is adopted. Mathieson et al. (2001) justified this occurrence claiming that after users have gained experience using a system, PU and PEOU are solely responsible for explaining intention. In this study, distant education students are not novel users and have experience using the LMS for more than two semesters. Therefore, this justifies the reason for excluding this factor in the development of the research model. Concurrently, as the LMS use was mandatory for the distance education program, Lemay et al. (2018) claim that technology acceptance models can explain the perception of acceptance and provide insights on the use and Attitude towards LMS effectively. Next, we also omitted out behavioral intention (BI) from our suggested model. According to Bazelais et al. (2018), BI is dependent on PU, PEOU, and user's beliefs about technology. However, Lemay et al. (2018) and Maruping et al. (2017) claim that in situations where the use of a system is compulsory, BI does not lead to actual use. Based on these findings, we decided to omit external factors and behavioral intentions in our model.

\section{METHODOLOGY}

In light of the considerations mentioned above, we examine the relationships among TAM factors using an explanatory sequential mixed-method research. Creswell and Clark (2011) defined mixed method as utilising the strength of quantitative and qualitative to obtain the best outcome as these methods can complement each other. The quantitative findings indicate factors influencing the attitude and the actual use of the LMS among distance education students, while the qualitative findings provide descriptive accounts of participants' use experiences, challenges, and recommendations.

\section{Quantitative Analysis}

We analysed the quantitative aspect based on the partial least squares (PLS) structural equation modeling approach (Hair et al., 2013). For that reason, we examined the acceptance of LMS by distance education based on the extended TAM model (Mathieson et al., 2001) by excluding BI and external variables. Next, based on the literature review, the study focused on the relationships between PU, PEOU, PR, AT, and the actual system use (USE) of the LMS. We adopted the original causal constructs, as stated by Hubona et al. (1996), based on the external stimulus-cognitive-affective-behavioural response relationships in TAM. Therefore, the following hypotheses are proposed and illustrated in Figure $\mathbf{2}$. 


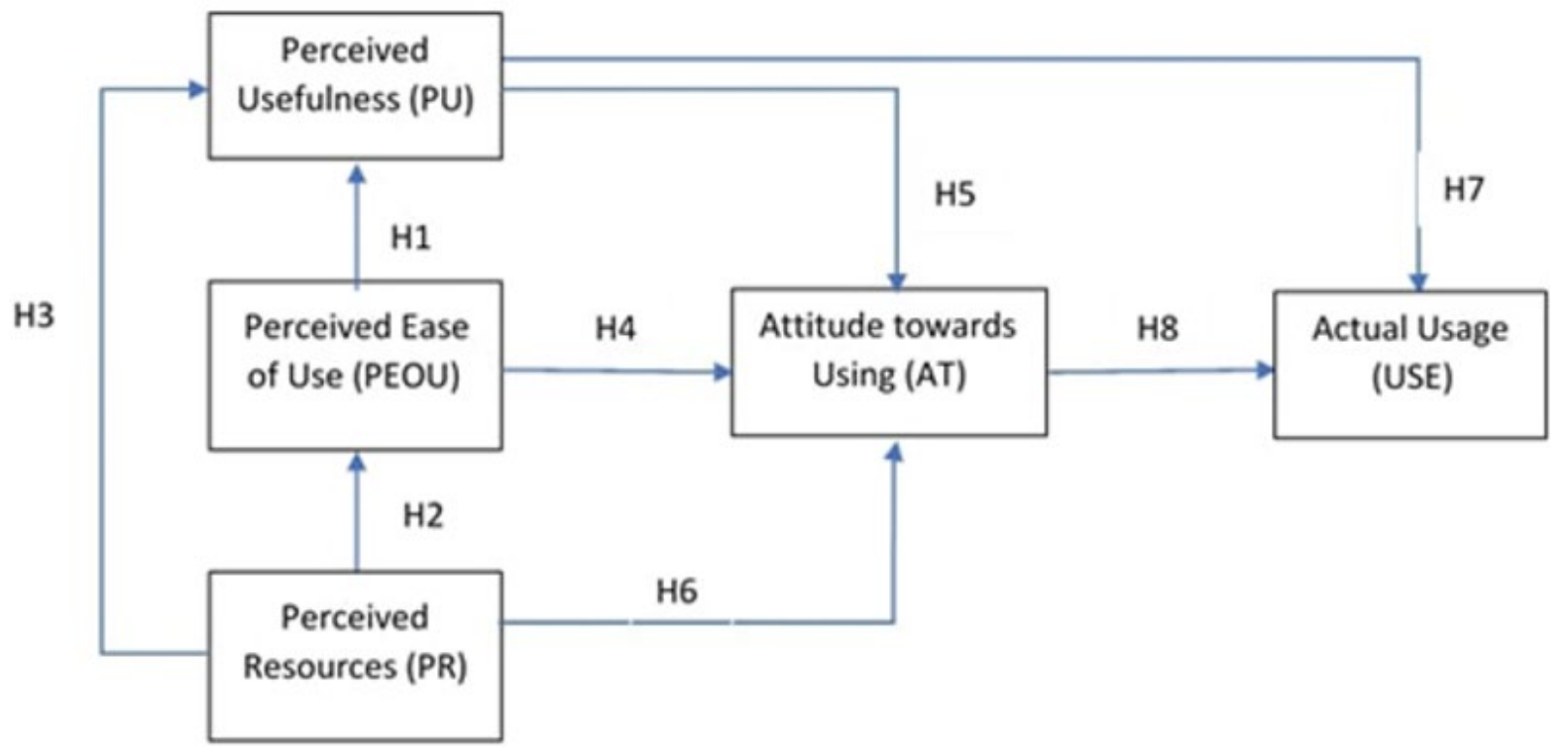

Figure 2. Hypothesis Model

H1 : Perceived Ease of Use will have a positive effect on Perceived Usefulness.

$\mathrm{H} 2$ : Perceived Resources will have a positive effect on Perceived Ease of Use

H3 : Perceived Resources will have a positive effect on Perceived Usefulness.

H4 : Perceived Ease of use will have a positive effect on Attitude.

H5 : Perceived Usefulness will have a positive effect on attitude.

H6: Perceived Resources will have a positive effect on Attitude.

H7 : Perceived Usefulness will have a positive effect on Actual Use.

H8 : Attitude will have a positive effect on Actual Use.

As for the survey instruments, we adopted the items from Sivo et al. (2018), which have shown reliability and validity evidence for LMS studies in the context of distance education. A total of 21 question items were used based on the five factors. All the items related to the four constructs were measured with a Likert scale ranging from 1 strongly disagree to 5 strongly agree. The targeted respondents were from a social science background and are in the $2^{\text {nd }}$ year of their program. The questionnaires were distributed electronically using Google forms through the LMS platform, and students were given two weeks to respond to the questionnaire. A second reminder was administered after two weeks to ensure a higher response rate.

\section{Demographic}

A total of 203 respondents participated in this study, where the response rate was $50.8 \%$ from the courses. Female respondents represented $56.2 \%(n=114)$ whereas males, $43.8 \%(n=89)$. The respondents between 30 to 39 years old held the highest percentage at $47.8 \%(\mathrm{~N}=97)$, and the second highest was those aged 2029 years old at $44.3 \%(\mathrm{~N}=90) .65 .3 \%(\mathrm{~N}=133)$ were government employees, while $34.7 \%(\mathrm{~N}=70)$ were employed in the private sector.

\section{Structural Equation Modelling}

Partial least squares (PLS) were used to examine the measurement and structural model due to its capabilities to accommodate smaller sample sizes without normality assumption (Chin et al., 2003). The software SmartPLS version 3.2.8 (Ringle et al., 2015) was used to test the model developed. We followed the suggestions of Hair et al. (2019) and Ramayah et al. (2018) by testing the model in two stages: 1) 
Measurement model (to assess validity and reliability of the measures) and then 2) Structural model (to test the hypotheses developed).

\section{Measurement Model}

To assess the measurement items and constructs, we tested for convergent validity. The test for reliability and convergent validity is presented in Table 1. In step one, we used loadings, composite reliability, and average variance extracted to assess convergent validity (Hair et al., 2018). All the item loadings exceeded 0.7 , and the AVE exceeded 0.5 for all constructs, thus indicating adequate convergent validity of the measurement model.

Table 1. Reliability and convergent validity

\begin{tabular}{lcccc}
\hline Constructs & Items & Loadings & CR & AVE \\
\hline Perceived Resources & PR1 & 0.745 & & \\
& PR2 & 0.706 & 0.862 & 0.611 \\
& PR3 & 0.822 & & \\
& PR4 & 0.845 & & \\
\hline Perceived Usefulness & PU1 & 0.746 & & 0.720 \\
& PU2 & 0.883 & 0.911 & \\
& PU3 & 0.895 & & \multirow{2}{*}{0.751} \\
& PU4 & 0.861 & & \multirow{2}{*}{0.840} \\
\hline Perceived Ease of Use & PEOU1 & 0.859 & 0.858 & \\
& PEOU2 & 0.874 & & \\
\hline Attitude & AT1 & 0.926 & & \multirow{2}{*}{0.870} \\
& AT2 & 0.904 & & \\
& AT3 & 0.920 & & \\
\hline Actual Use & USE1 & 0.928 & 0.931 & \\
& USE2 & 0.937 & & \\
\hline
\end{tabular}

In step two, we assessed the discriminant validity using the Heterotrait - Monotrait ratio (HTMT) criterion suggested by Henseler et al. (2014) and updated by Franke and Sarstedt (2019). The HTMT values should be $\leq 0.85$, the stricter criterion, and the mode lenient criterion should be $\leq 0.90$. As shown in Table 2 , the values of HTMT were all lower than the stricter criterion of $\leq 0.85$; thus, we can conclude that the respondents understood that the five constructs are distinct. Taken together both these validity test has shown that the measurement items are both valid and reliable.

Table 2. Discriminant Validity

\begin{tabular}{lccccc}
\hline Constructs & 1 & 2 & 3 & 4 & 5 \\
\hline 1. Actual Usage & & & & & \\
2. Attitude & 0.620 & & & & \\
3. Perceived Usefulness & 0.586 & 0.688 & & & \\
4. Perceived Ease of Use & 0.796 & 0.818 & 0.833 & & \\
5. Perceived Resources & 0.573 & 0.736 & 0.710 & 0.823 & \\
\hline
\end{tabular}

\section{Qualitative analysis}

Thereafter, the qualitative analysis is composed of distance education students' responses on their views of the LMS for teaching and learning in regard to strengths, limitations, expectations, and recommendations. We applied Braun and Clarke (2006) five-staged of thematic analysis. The questions asked during the interview are:

1. What are the perceived benefits of the LMS platform?

2. What are their perceived challenges of using LMS in their learning activities?

3. What are students' recommendations to improve learning via LMS?

To ensure reliability in the interview process, we applied the four primary validation criteria described by Leininger (1994): trustworthiness, credibility, applicability, and consistency. Trustworthiness and credibility 
were achieved by providing verbatim quotations to support interpretation (Hammarberg et al., 2016) and based on researchers' experiences in interview protocols (Exter \& Ashby, 2019). Next, the applicability and consistency were also validated as the questions reflected on the LMS user experience where all the respondents were exposed to the same LMS and content. Next, purposeful sampling was intentionally selected where a total of 15 respondents were identified for the interview (Creswell \& Clark, 2011). The interview duration was between 30 and 45 minutes, where the sessions were audio-recorded, transcribed using oTranscibe.com, and reviewed based on the research aim to identify themes that support the acceptance and use of LMS.

\section{RESULTS AND DATA ANALYSIS}

Data analysis is discussed based on the structural model used to identify the overall acceptance of LMS, followed by a thematic analysis to explore the perception, challenges, and recommendations used to support the quantitative findings.

\section{Structural Model}

We tested the hypothesis by running a bootstrapping procedure with 5,000 resamples (Hair et al., 2018; Ramayah et al., 2018). The bootstrapping will produce the beta values, standard errors, $t$-values, $p$-values, and effect sizes. As shown in Table 3 , there was a positive relationship between PEOU and PU $(B=0.682, p \leq$ $0.01)$. PR has a positive relationship PEOU $(B=0.653, p \leq 0.01)$ and $\mathrm{PU}(B=0.147, p \leq 0.05)$; thus, $\mathrm{H} 1, \mathrm{H} 2$ and $\mathrm{H} 3$ were supported. We then tested the effect of PEOU $(B=0.487, p \leq 0.01), \mathrm{PU}(B=0.074, p \geq 0.05)$ and PR $(B=0.266, p \leq 0.01$ ) on Attitude, only $\mathrm{H} 4$ and $\mathrm{H} 6$ were supported while $\mathrm{H} 5$ was not supported. Finally, we tested the effect of PU $(\beta=0.272, p \leq 0.01)$ and Attitude PR $(\beta=0.380, p \leq 0.01)$ on Actual Usage, and both were positively related to USE; thus, $\mathrm{H} 7$ and $\mathrm{H} 8$ were also supported.

Table 3. Hypothesis Testing

\begin{tabular}{lcccccccc}
\hline Relationship & Std. Beta & Std. Error & t-value & p-value & BCl LL & BCl UL & $f^{2}$ & Results \\
\hline H1: PEOU $\rightarrow$ PU & 0.682 & 0.056 & 12.087 & 0.000 & 0.571 & 0.760 & 0.698 & S \\
\hline H2: PR $\rightarrow$ PEOU & 0.653 & 0.049 & 13.328 & 0.000 & 0.555 & 0.719 & 0.742 & S \\
\hline H3: PR $\rightarrow$ PU & 0.147 & 0.070 & 2.094 & 0.018 & 0.029 & 0.266 & 0.032 & S \\
\hline H4: PEOU $\rightarrow$ AT & 0.487 & 0.083 & 5.890 & 0.000 & 0.359 & 0.644 & 0.183 & S \\
\hline H5: PU $\rightarrow$ AT & 0.074 & 0.100 & 0.740 & 0.230 & -0.125 & 0.210 & 0.005 & NS \\
\hline H6: PR $\rightarrow$ AT & 0.266 & 0.078 & 3.403 & 0.000 & 0.144 & 0.390 & 0.090 & $\mathrm{~S}$ \\
\hline H7: PU $\rightarrow$ USE & 0.272 & 0.098 & 2.764 & 0.003 & 0.108 & 0.431 & 0.071 & $\mathrm{~S}$ \\
\hline H8:AT $\rightarrow$ USE & 0.380 & 0.100 & 3.819 & 0.000 & 0.205 & 0.538 & 0.139 & $\mathrm{~S}$ \\
\hline
\end{tabular}

*Note: $\mathrm{S}=$ Supported, NS = Not Supported

The $\mathrm{R}^{2}$ for predicting PEOU was 0.426 , and PU was 0.617 , indicating that $42.6 \%$ of the variance in PEOU can be explained by PR while $61.7 \%$ of the variance in PU can be explained strongly by PEOU and PR. Based on the path coefficient value it The $R^{2}$ for the prediction of attitude was 0.562 while for Actual Usage was 0.345 , which shows that $56.2 \%$ of the variance in attitude can be explained strongly by PE and followed by PR while only $34.5 \%$ of the variance in Actual Usage can be explained by the modeled variables namely AT and PE.

\section{Analysis of the Interviews}

According to Miles and Huberman (1994), quantitative and qualitative methods complement each other to take advantage of each other. Semi-structured interviews were conducted with 15 students. On the whole, students admitted that the LMS helped them in their learning process. They gave positive feedback that includes ease of use and usefulness of the system in distance learning facilitation. Ease of use was deemed related to accessibility, navigation, and online learning management. Learning management of online learning was related to assignment submission and the availability of an academic planner. A key feature of the responses was associated with the forum and chat discussion for collaborative work. Example of students' responses are: 
SAS 3: We are able to open the portal anytime. There are additional notes from the lecturers. Academic planner is also there.

SAS 5: Easy to submit assignments.

SAS1: It is easy to find group members for assignments.

SAS2: Easy to discuss in the forum.

During the interview, the most frequent explanation of the LMS's usefulness was related to the unlimited access to tape-recorded videos that allowed them to stream the videos without downloading it. Students also found the LMS was useful to access learning contents, assignment scores, quizzes, and appointments with lecturers. The following excerpts explain the reasons why they appreciate the LMS:

SAS 6: You don't need to download the videos. You can just watch it.

SAS 12: Open to know our scores for assignments.

SAS13: Lecturers calling to complete assignments, complete quizzes.

SAS 14: It is useful ... because one day before the lecture, I can check the portal for updates.

The respondents also were questioned on their challenges of using the LMS. They expressed their frustration when materials were not up to date, technical difficulties, the lecturer's ineffective use of activity modules, and the platform's obsolete features. We observe that these challenges can be linked to limitations that resulted in perceived resources not supporting the actual use. As an example, technology glitches were highlighted during the interview. Participants highlighted the poor Internet connectivity. Due to high usage at the same time, learning activities related to assessment and intensive were problematic. There were also problems related to the assignment submission. Some of the comments are:

SAS7: we can't open the portal during intensive (peak sessions) where quizzes cannot be completed at that particular time and end up getting zero.

SAS11: during intensive, it is very difficult to access the portal. For oral assessment, there are issues with recording, where the system does not capture my voice.

SAS14: sometimes, the assignment cannot be submitted.

The interview also indicated a lack of communication between lecturers and students. Lecturers were not managing the LMS effectively, and this includes delivering inappropriate content. Students were challenged by the incompetence of lecturers in regard to providing more relevant learning content and commitment.

SA9: lecturers do not update the system accordingly ... this was confusing and some of the students were working on the last semester's assignments.

SAS13: lecturers need to update the portal so that the students are updated on changes.

In addition to this, dissatisfaction was also noted on the out-dated approach of teaching and learning activities and lack of richness in interaction as lecture notes are still given as Microsoft Word and PowerPoint documents. The interview found that students were trying to compare the LMS with newer technology usability features, particularly related to smartphones and mobile applications. This can be observed in the following statement.

SAS1: Out-dated methods such as Microsoft Word and PowerPoint, nothing interactive.

SAS6: I don't need to open the platform frequently. I only open it to get my scores as there is nothing interesting or changed from last semester. 
SAS5: Not compatible. The platform only supports desktop settings.

While acknowledging LMS limitations, the participants generated a series of worthwhile suggestions that can further enhance the LMS use. When questioned, students mainly highlighted the need to integrate mobile technology, requesting a mobile version of the LMS, which incorporates academic and communication applications to facilitate their learning process. In a way, this application will facilitate their assignment preparation process, such as plagiarism and referencing software. Besides, they would also like the platform to advertise events happening in the university. They stated that:

\section{SAS3: Include some apps related to academics. For example, plagiarism check, bench link, Mendeley, and student loan matters link.}

SAS5: Moodle should update events in the university.

SAS6. It would be good if there is Moodle app where we can use it anytime, anywhere.

SAS7: We want a chatbox like WhatsApp.

SAS10. Most of us using smartphones, so the setting needs to be in a mobile setting.

SAS13: we want easy access like smartphones, no need to scroll up and down looking for information.

\section{DISCUSSION AND IMPLICATION}

According to Bazelais et al. (2018), to ensure the success and effective use of an online learning environment, users' interest and acceptance of the system should be investigated. Therefore, to make sense of the findings, we discuss the quantitative analysis as supported by the finding from the interviews. We found all relationships between the factors supported, except for PU towards AT. The relationship between AT (interest towards the system) and PU (LMS's usefulness) was not significant due to the compulsory nature of the LMS for distance education. Nevertheless, AT could be predicted based on perceived ease of use and resources. According to Bazelais et al. (2018), students would be more interested in using an online system if they perceive the system as advantageous, user-friendly, and effortless. We do not deny this, but in some cases where the LMS is the central platform providing interaction for teaching and learning, students would view the system as applicable as they do not have any other alternatives. Therefore, eliminating functionality and emphasizing factors related to online resources that are available through the LMS.

Subsequently, we observed that the most substantial significant relationship is denoted between PR and PEOU, followed by PEOU with PU. The relationship between PEOU and PU has been well documented in empirical findings of LMS (Almarashdeh \& Alsmadi, 2016). Interestingly, PR has the weakest significant relationship with PU in the model, indicating that perceived resources do not directly influence usefulness but moderate ease of accessing the LMS. Henceforth, our findings agree with Sivo et al. (2018) that perceive resources do influence perception of usefulness; however, we observe that it predicts ease of use better. On the contrary, we also observed attitude as a better predictor of the system's actual use than usefulness. The weak significant relationship between PU and USE also explains that due to the compulsory nature of the LMS, the main factors in determining AT and USE are PEOU and PR. This was supported by Yalcin and Kutlu (2019) as the number of resources in the LMS and the ease of using it to achieve learning goals influences intention to use the LMS. We gather that with resources denoting skills, time, learning contents, and software, effective LMS interaction is vital.

Conversely, interview findings were substantial in validating these outcomes. Firstly, we questioned students on the perceived advantage of using LMS (RQ1). We gathered students' views of ease of accessing learning contents, assignment submission, and creating online learning communities through the LMS as beneficial. Hence, the supporting the strong positive relationship between PEOU and PU is supported. In terms of resources, we note that students welcomed the idea of video streaming and the use of mobile 
communication platforms. Furthermore, easy access to their graded scores and contents were also found to relate to ease of executing these tasks. Henceforth, supporting the strength of $\mathrm{H} 1$ and $\mathrm{H} 3$ as more emphasis is given on the ease of use than usefulness. To obtain a more in-depth understanding, we questioned the challenges that influenced their use of the LMS (RQ2) and deduced that technical issues related to access and out-dated teaching materials and delivery as the primary concern. It was revealed that the LMS's incompetency in supporting a large number of students hindered accessing learning activities at critical points of assessment. We gathered that these challenges might have contributed to a weaker relationship on PU towards USE (H7). Cigdem and Ozturk (2016) assert that if students are not confident about their capabilities of using LMS or view the interaction as problematic, they would prefer not to use the system.

Furthermore, the lecturers' use of the LMS was found not to meet the distance education students' expectations. According to Ferianda et al. (2018), engagement in learning activities predicts students' perception of the LMS's usefulness for distance learning. The interview findings indicated that learning strategies are not impactful due to a lack of interactive activities. Besides, it also indicates the need for instructors to design meaningful, innovative, and up-to-date content by not using the LMS as an inventory of learning material. This result confirms that lecturers' competencies and skills are a critical component for teaching online successfully (Kim \& Thayne, 2015; Menchaca \& Bekele, 2008). Moreover, it is highly essential to ensure teachers' presence through responsive communication and active participation in online learning communities to ensure students are intrinsically motivated (Belaja et al., 2012). We gathered that the teaching presence is lacking and may have contributed towards attitude towards the learning contents. Interestingly, none of the respondents mentioned issues with internet services, and we deduced this towards having better financial standing to access such facilities as working adults.

Henceforth, we questioned their recommendation in improving the use of LMS (RQ3). According to Bazelais et al. (2018), it is imperative to align and create awareness of how undergraduates interact with the learning platforms. We observed that most respondents suggested using mobile applications to facilitate their distance learning program, and this idea was also supported by Chung et al. (2020), Olivier (2016), and Yacob et al. (2020). We noticed that respondents recommended that the application facilitate mobile interaction (responsive design) or mobile application. As today's learners are more tuned to mobile technologies, their interest in utilizing such technology greatly impacts their use. These findings support the findings of Annamalai and Kumar (2020) in regard to LMS access for distance learning using mobile devices. Conversely, as distance education students are physically 'out of campus,' they need to perceive themselves as part of the institute's ecosystem. This was reflected by suggestions to embed information regarding events and a platform to communicate with their learning community to avoid isolation from their physical learning environment. Furthermore, access to learning tools, especially plagiarism checkers, referencing tools, and other learning software, was also deemed imperative to facilitate learning as they could not access such facilities remotely. We stipulate that the issues related to distance learning is related primarily to access of resources, followed by teaching and learning quality.

\section{CONCLUSION, LIMITATION AND FUTURE DIRECTION}

Overall, we found that the extended TAM explained a significant amount of variance in distance education students' attitudes $\left(R^{2}=56.2 \%\right)$ and actual use $\left(R^{2}=34.5 \%\right)$. Therefore, we deemed the $R^{2}$ achieved in our model as sufficient, given the complexity of the proposed model was small. The model depicts that perceived resources have the strongest relationship with perceived ease of use, which critically influences attitude and use. Conversely, perceived usefulness was found not to support attitude and had a weak relationship with USE and perceived resources, hence questioning the need to include the PU in future studies where the information system's use is compulsory. Next, challenges were deemed to be related to accessibility, outdated interactive learning contents, and mobile-based interaction. We recommend future studies to consider factors such as self-efficacy, technology competency, perceived learning opportunities, social influence (online community), and online learning ecosystem as strategies to explore LMS use for distance education further. This was derived based on the recommendation to improve their role as a learner secluded from the institution ecosystem. 
Henceforth, this study contributes to the limited studies on distance education in Malaysia, focusing on students' perspectives on using the LMS as a compulsory learning tool. The mixed-method approach solidifies the relationships observed by emphasising the need to design and integrate learning activities that are interactive and easily accessible based on the affordance of $21^{\text {st }}$-century learning strategies. The study also ascertains that perceived usefulness is not a mandatory factor to be considered for distance education due to the compulsory nature of the LMS, as also suggested by Nicholas-Omoregbe et al. (2017). Furthermore, the study highlights the current model gaps that neglect social presence, personality factors, and social influence relating to their online learning ecosystem. However, this study is limited by the use of convenience sampling from one institution. We hope that future studies will incorporate other technology antecedents such as self-efficacy, personalization, and social interaction. Future studies could also explore the role of mobile learning habits and other perceived resources towards LMS use. Furthermore, we envisage mobilebased LMS platform would strengthen the relationship between perceived usefulness and attitude. We conclude by depicting that the attitude and use of information systems for learning tend to focus on the ease of performing the learning task, affordance of the technology (e.g., mobile applications), and inclusivity in the learning environment.

\section{LIST OF ABBREVIATIONS}

USE : Actual Use

AT : Attitude

HTMT : Heterotrait - Monotrait ratio

LMS : Learning Management Systems

MOOCs : Massive Open Online Courses

PU : Perceived Usefulness

PEOU : Perceived Ease of Use

PR : Perceived Resources

TAM : Technology Acceptance Model

Author contributions: All authors were involved in concept, design, collection of data, interpretation, writing, and critically revising the article. All authors approve final version of the article.

Funding: No funding was received for this study.

Declaration of interest: The authors report no conflicts of interest.

Data availability: Data generated or analysed during this study are available from the authors on request.

\section{REFERENCES}

Abdul Lasi, M. (2021). Online distance learning perception and readiness during Covid-19 outbreak: A research review article in international journal of academic research in progressive education and development. International Journal of Academic Research in Progressive Education and Development, 10(1), 63-73. https://doi.org/10.6007/IJARPED/v10-i1/8593

Al-Busaidi, K. A. (2013). An empirical investigation linking learners' adoption of blended learning to their intention of full e-learning. Behaviour \& Information Technology, 32(11), 1168-1176. https://doi.org/10.1080/0144929X.2013.774047

Almarashdeh, I., \& Alsmadi, M. (2016). Investigating the acceptance of technology in distance learning program. 2016 International Conference on Information Science and Communications Technologies, ICISCT 2016, 1-5. https://doi.org/10.1109/ICISCT.2016.7777404 
Annamalai, N., \& Kumar, J. A. (2020). Understanding smartphone use behavior among distance education students in completing their coursework in English: a mixed-method approach. Reference Librarian, 61(3-4), 199-215. https://doi.org/10.1080/02763877.2020.1815630

Aybay, I., \& Dağ, O. O. (2003). A learning management system developed at the Eastern Mediterranean University. The Turkish Online: A Learning Management System, 2(2), 14-19.

Bazelais, P., Doleck, T., \& Lemay, D. J. (2018). Investigating the predictive power of TAM: A case study of CEGEP students' intentions to use online learning technologies. Education and Information Technologies, 23(1), 93-111. https://doi.org/10.1007/s10639-017-9587-0

Belaja, K., Teoh, G., Sai, B., Liau, A., \& Lin, W. (2012). Effects of the lecturer's transactional presence towards learners' intrinsic motivation in learning english as a second language through distance education. Malaysian Journal of Distance Education, 14(1), 77-97.

Bervell, B., \& Arkorful, V. (2020). LMS-enabled blended learning utilization in distance tertiary education: establishing the relationships among facilitating conditions, voluntariness of use and use behaviour. International Journal of Educational Technology in Higher Education, 17(1). https://doi.org/10.1186/s41239-020-0183-9

Bervell, B., \& Umar, I. N. (2018). Utilization decision towards LMS for blended learning in distance education: Modeling the effects of personality factors in exclusivity. Knowledge Management and E-Learning, 10(3), 309-333. https://doi.org/10.34105/j.kmel.2018.10.018

Braun, V., \& Clarke, V. (2006). Using thematic analysis in psychology. Qualitative Research in Psychology, 3(2), 77-101. https://doi.org/10.1191/1478088706qp063oa

Brophy, J. (1999). Toward a model of the value aspects of motivation in education: Developing appreciation for particular learning domains and activities. Educational Psychologist, 34(2), 75-85. https://doi.org/10.1207/s15326985ep3402_1

Chin, W. W., Marcolin, B. L., \& Newsted, P. R. (2003). A partial least squares latent variable modeling approach for measuring interaction effects: results from a Monte Carlo simulation study and an electronic-mail emotion/adoption study. Information Systems Research, 14(2), 189-217. https://doi.org/10.1287/isre.14.2.189.16018

Chung, E., Subramaniam, G., \& Dass, L. C. (2020). Online learning readiness among university students in Malaysia amidst Covid-19. Asian Journal of University Education (AJUE), 16(2), 46-58. https://doi.org/10.24191/ajue.v16i2.10294

Cigdem, H., \& Ozturk, M. (2016). Factors affecting students' behavioral intention to use Ims at a turkish postsecondary vocational school. International Review of Research in Open and Distributed Learning, 17(3). https://doi.org/10.19173/irrodl.v17i3.2253

Creswell, J. W., \& Clark, V. L. P. (2011). Designing and Conducting Mixed Methods Research (2nd ed.). SAGE Publications.

Davis, F.D. (1985). A technology acceptance model for empirically testing new end-user information systems: Theory and results. Massachusetts Institute of Technology.

Davis, Fred D., Bagozzi, R. P., \& Warshaw, P. R. (1989). User acceptance of computer technology: A comparison of two theoretical models. Management Science, 35(8), 982-1003. https://doi.org/10.1287/mnsc.35.8.982

Escobar-Rodriguez, T., \& Monge-Lozano, P. (2012). The acceptance of Moodle technology by business administration students. Computers \& Education, 58(4), 1085-1093. https://doi.org/10.1016/j.compedu.2011.11.012 
Exter, M. E., \& Ashby, I. (2019). Preparing today's educational software developers: voices from the field. Journal of Computing in Higher Education, 31(3), 472-494. https://doi.org/10.1007/s12528-018-91989

Ferianda, M. R., Herdiani, A., \& Sardi, I. L. (2018). Increasing students interaction in distance education using gamification. 2018 6th International Conference on Information and Communication Technology (ICoICT), O(c), 125-129. https://doi.org/10.1109/ICoICT.2018.8528765

Fernando, Z. F., Rosalba, C. C., Francisco, L. T., Andres, V. F., \& Dionicio, Z. F. (2008). u-Teacher: Ubiquitous learning approach. In Technologies for e-learning and digital entertainment. Edutainment 2008 (Lecture No, pp. 9-20). Springer. https://doi.org/10.1007/978-3-540-69736-7_2

Fleischmann, K. (2018). Hype or help? technology enhanced learning in the classroom: An experiment in online design collaboration hype or help? International Journal of Arts \& Sciences, 11(1), 331-341.

Franke, G., \& Sarstedt, M. (2019). Heuristics versus statistics in discriminant validity testing: a comparison of four procedures. Internet Research, 29(3), 430-447. https://doi.org/10.1108/IntR-12-2017-0515

Gros, B., \& García-Peñalvo, F. J. (2016). Future trends in the design strategies and technological affordances of e-learning. In M. J. Spector, B. B. Lockee, \& M. D. Childress (Eds.), Learning, design, and technology. An international compendium of theory, research, practice, and policy (pp. 1-23). Springer International Publishing. https://doi.org/https://doi.org/10.1007/978-3-319-17727-4_67-11

Hair, J. F., Ringle, C. M., \& Sarstedt, M. (2013). Partial least squares structural equation modeling: rigorous applications, better results and higher acceptance. Long Range Planning, 46(1-2), 1-12. https://doi.org/10.1016/j.Irp.2013.01.001

Hair, J. F., Risher, J. J., Sarstedt, M., \& Ringle, C. M. (2018). When to use and how to report the results of PLSSEM. European Business Review, 31(1), 2-24. https://doi.org/10.1108/EBR-11-2018-0203

Hammarberg, K., Kirkman, M., \& De Lacey, S. (2016). Qualitative research methods: When to use them and how to judge them. Human Reproduction, 31(3), 498-501. https://doi.org/10.1093/humrep/dev334

Henseler, J., Ringle, C. M., \& Sarstedt, M. (2014). A new criterion for assessing discriminant validity in variance-based structural equation modeling. Journal of the Academy of Marketing Science, 43(1), 115135. https://doi.org/10.1007/s11747-014-0403-8

Hubona, G. S., \& Kennick, E. (1996, January). The influence of external variables on information technology usage behavior. In Proceedings of HICSS-29: 29th Hawaii International Conference on System Sciences (Vol. 4, pp. 166-175). IEEE. https://doi.org/10.1109/HICSS.1996.495323

Ifinedo, P., Pyke, J., \& Anwar, A. (2018). Business undergraduates' perceived use outcomes of Moodle in a blended learning environment: The roles of usability factors and external support. Telematics and Informatics, 35(1), 93-102. https://doi.org/10.1016/j.tele.2017.10.001

Leininger, M. (1994). Evaluation criteria and critique of qualitative research studies. In J. M. Morse (Ed.), Critical issues in qualitative research methods. Sage.

Kim, Y., \& Thayne, J. (2015). Effects of learner-instructor relationship-building strategies in online video instruction. Distance Education, 36(1), 100-114. https://doi.org/10.1080/01587919.2015.1019965

Ku, C.-H. (2009). Extending the Technology Acceptance Model using perceived user resources in higher education web-based online learning courses [Doctoral dissertation, University of Central Florida]. UCF Repository. https://stars.library.ucf.edu/etd/3867

Kumar, J. A. \& Al-Samarraie, H. (2018). MOOCs in the Malaysian higher education institutions: The instructors' $\begin{array}{llll}\text { perspectives. The } & \text { 163-177. }\end{array}$ https://doi.org/10.1080/02763877.2018.1458688 
Kumar, J.A., Bervell, B., \& Osman, S. (2020). Google classroom: Insights from Malaysian higher education students' and instructors' experiences. Education and Information Technologies, 25(5), 4175-4195. https://doi.org/10.1007/s10639-020-10163-x

Lee, Y.-C. (2008). The role of perceived resources in online learning adoption. Computers \& Education, 50(4), 1423-1438. https://doi.org/10.1016/j.compedu.2007.01.001

Lemay, D. J., Morin, M. M., Bazelais, P., \& Doleck, T. (2018). Modeling students' perceptions of simulationbased learning using the technology acceptance model. Clinical Simulation in Nursing, 20, 28-37. https://doi.org/10.1016/j.ecns.2018.04.004

Maruping, L. M., Bala, H., Venkatesh, V., \& Brown, S. A. (2017). Going beyond intention: Integrating behavioral expectation into the unified theory of acceptance and use of technology. Journal of the Association for Information Science and Technology, 68(3), 623-637. https://doi.org/10.1002/asi.23699

Mathieson, K., Peacock, E., \& Chin, W. W. (2001). Extending the technology acceptance model: The influence of perceived user resources. Data Base for Advances in Information Systems, 32(3), 86-112. https://doi.org/10.1145/506724.506730

Menchaca, M. P., \& Bekele, T. A. (2008). Learner and instructor identified success factors in distance education. Distance Education, 29(3), 231-252. https://doi.org/10.1080/01587910802395771

Miles, M. B., \& Huberman, A. M. (1994). Qualitative Data Analysis: An Expanded Sourcebook (2nd ed.). SAGE Publication.

Morris, M. G., \& Venkatesh, V. (2010). Job characteristics and job satisfaction: understanding the role of enterprise resource planning system implementation. MIS Quarterly, 34(1), 143. https://doi.org/10.2307/20721418

Mukoviz, O., Ihnatenko, N., \& Kovtun, O. (2019). Selection of the distance learning management system for pedagogical higher education institutions. Open Educational E-Environment of Modern University, special edition, 215-221. https://doi.org/10.28925/2414-0325.2019s20

Nicholas-Omoregbe, O. S., Azeta, A. A., Chiazor, I. A., \& Omoregbe, N. (2017). E-learning management system: A case of selected private universities in Omoregbe, Nigeria. Turkish Online Journal of Distance Education, 18(2), 106-121.

Novo-Corti, I., Varela-Candamio, L., \& Ramil-Díaz, M. (2013). E-learning and face to face mixed methodology: Evaluating effectiveness of e-learning and perceived satisfaction for a microeconomic course using the Moodle platform. Computers in Human Behavior, 29(2), 410-415. https://doi.org/10.1016/j.chb.2012.06.006

Olivier, J. (2016). Blended learning in a first-year language class: Evaluating the acceptance of an interactive learning environment. Literator - Journal of Literary Criticism, Comparative Linguistics and Literary Studies, 37(2). https://doi.org/10.4102/lit.v37i2.1288

Park, J. H., \& Choi, H. J. (2009). Factors influencing adult learners' decision to drop out or persist in online learning. Educational Technology and Society, 12(4), 207-217.

Rahman, K. A., Ghazali, S. A. M., \& Ismail, M. N. (2010). The effectiveness of learning management system (LMS) case study at Open University Malaysia (OUM), Kota Bharu Campus. Journal of Emerging Trends in Computing and Information Sciences, 2(2), 73-79.

Ramayah, T., Cheah, J., Chuah, F., Ting, H., \& Memon, M. A. (2018). Partial Least Squares Structural Equation Modeling (PLS-SEM) using SmartPLS 3.0: An updated guide and practical guide to statistical analysis. Pearson. 
Ringle, C. M., Wende, S., \& Becker, J. M. (2015). SmartPLS 3. SmartPLS GmbH.

Saidi, R. M., Sharip, A. A., Abd Rahim, N. Z., Zulkifli, Z. A., \& Md Zain, S. M. (2021). Evaluating students' preferences of open and distance learning (ODL) Tools. Procedia Computer Science, 179(2019), 955961. https://doi.org/10.1016/j.procs.2021.01.085

Sivo, S. A., Ku, C. H., \& Acharya, P. (2018). Understanding how university student perceptions of resources affect technology acceptance in online learning courses. Australasian Journal of Educational Technology, 34(4), 72-91. https://doi.org/10.14742/ajet.2806

Smith, J. A., \& Sivo, S. A. (2012). Predicting continued use of online teacher professional development and the influence of social presence and sociability. British Journal of Educational Technology, 43(6), 871882. https://doi.org/10.1111/j.1467-8535.2011.01223.x

Sobaih, A. E. E., Moustafa, M. A., Ghandforoush, P., \& Khan, M. (2016). To use or not to use? Social media in higher education in developing countries. Computers in Human Behavior, 58, 296-305. https://doi.org/10.1016/j.chb.2016.01.002

Tarhini, A., Hone, K., \& Liu, X. (2015). A cross-cultural examination of the impact of social, organisational and individual factors on educational technology acceptance between British and Lebanese university $\begin{array}{llll}\text { students. British Journal of Educational Technology, 46(4), } & \text { 755. }\end{array}$ https://doi.org/10.1111/bjet.12169

Thah, S. S., \& Latif, L. A. (2020) Learning outcomes in distance learning: a study of learners' experience. In K. C. Li, E. Y. M. Tsang, \& B. T. M. Wong (Eds.), Innovating Education in Technology-Supported Environments. Education Innovation Series. Springer. https://doi.org/10.1007/978-981-15-6591-5_2

Viberg, O., \& Grönlund, Å. (2017). Understanding students' learning practices: challenges for design and integration of mobile technology into distance education. Learning, Media and Technology, 42(3), 357377. https://doi.org/10.1080/17439884.2016.1088869

Waheed, M., Kaur, K., Ain, N., \& Hussain, N. (2016). Perceived learning outcomes from Moodle. Information Development, 32(4), 1001-1013. https://doi.org/10.1177/0266666915581719

Washington, G. Y. (2019). The learning management system matters in face-to-face higher education courses. Journal of Educational Technology Systems, 1-21. https://doi.org/10.1177/0047239519874037

Weng, F., Yang, R.-J., Ho, H.-J., \& Su, H.-M. (2018). A TAM-based study of the attitude towards use intention of multimedia among school teachers. Applied System Innovation, 1(3), 36. https://doi.org/10.3390/asi1030036

Yacob, N. H. M., Syazwani, N., Fadzillah, M., Hawani, N., Abdul, W., Mustafa, L. M., Jamaluddin, S., Barieyah, A., \& Bahari, M. (2020). Learning experience and barriers throughout open distance learning mode: A case study of UITM Pahang. GADING (Online) Journal of Social Sciences, 23(2), 25-33.

Yalcin, M. E., \& Kutlu, B. (2019). Examination of students' acceptance of and intention to use learning management systems using extended TAM. British Journal of Educational Technology, 50(5), 24142432. https://doi.org/10.1111/bjet.12798

Zwain, A. A. A. (2019). Technological innovativeness and information quality as neoteric predictors of users' acceptance of learning management system: An expansion of UTAUT2. Interactive Technology and Smart Education, 16(3), 239-254. https://doi.org/10.1108/ITSE-09-2018-0065

Correspondence: Jeya Amantha Kumar, Centre for Instructional Technology and Multimedia, Universiti Sains Malaysia, Pulau Pinang, Malaysia. E-mail: jeya.amantha@gmail.com 